\title{
EL CEREBRO Y LA CONCIENCIA: \\ UNA PROPUESTA INTEGRADORA ENTRE DAMÁSIO Y ZUBIRI
}

\author{
ANTONIO JÁCOMO \\ University Institute of Health Sciences, \\ Toxicology Research Unit, CESPU, CRL \\ CARLOS SANMARTÍN CATALÁN \\ Universitat de València
}

\begin{abstract}
RESUMEN: El estudio del sistema nervioso y sus funciones es fascinante y complejo. Uno de los asuntos más intrigantes de este campo es cómo la neurobiología produce estados conscientes. Para el estudio del complejo problema de la conciencia, son necesarios conocimientos tanto de neuroanatomía y fisiología como de lingüística y filosofía, lo que lo convierte en un problema temido o sencillamente ignorado tanto por científicos como por filósofos. Pero este desprecio del problema, lejos de resolverlo, desemboca en una reflexión reduccionista, que trata de ver un dilema donde hay un problema. En este artículo pretendemos aproximar las neurociencias y la filosofía, en el sentido de comprender cuál es la contribución que cada una puede ofrecer y, al mismo tiempo, sistematizar el conocimiento que de esta relación podemos extraer. Para ello, nos centraremos en las reflexiones del neurocientífico Damásio, especialmente de su concepto de conciencia ampliada, pero también en la teoría filosófica de Zubiri, y sus conceptos de biografía, «inteligencia sentiente» e «intimidad».
\end{abstract}

PALABRAS CLAVE: conciencia ampliada; neurociencia; intimidad; inteligencia sentiente.

\section{Brain and conciousness: an integrative proposal between Damasio and Zubiri}

ABSTRACT: The study of the nervous system and their functions is fascinating and complex. One of the most intriguing issues is how neurobiology produces conscious states. To study the behaviour of the complex problem of conciousness, we must have knowledge both in neuroanatomy, physiology lingüistics and philosophy, which makes it a feared problem which is occasionally ignored by sciencists and philosophers. But despising of the problem, far from sorting it out, leads to a reductionist reflection, that tries to see a dilemma where there is, actually, a problem. In this article, we intend to connect neurosciences and philosophy, in order to understand each contribution on this matter and, at the same time, systematize the knowledge obtained through this relation. Therefore, we will focus on Damásio's work, especially in his concept of «expanded conciousness", and on the philosophy of Zubiri, and his concepts of «biography», "sentient intelligence», and «intimacy».

KEY WORDS: Expanded Consciousness; Neuroscience; Intimacy; Sentient Intelligence.

El jardín de la neurología brinda al investigador espectáculos cautivadores y emociones artísticas incomparables. (...) ¡Como el entomólogo a la caza de mariposas de vistosos colores, mi atención perseguía, en el vergel de la substancia gris, células de formas delicadas y elegantes, las misteriosas mariposas del alma, cuyo batir de alas quién sabe si esclarecerá algún día el secreto de la vida mental! ${ }^{\text {. }}$

1 Ramón y Cajal, S., Recuerdos de mi vida, N. Moya, Madrid, 1917, pp. 155-156. 
INTRODUCCIÓN

La primera cuestión con que nos enfrentamos es que la cantidad de información surgida de los avances en la investigación de las neurociencias es grande, y los puntos de partida, en general, pueden ser múltiples: como la biología, la psicología o la filosofía. Desde este horizonte, el presente artículo tiene como objetivo estudiar las mutuas relaciones de las neurociencias y de la filosofía a través del pensamiento del neurocientífico Antonio Damásio y del filósofo Xavier Zubiri.

Xavier Zubiri, ya en su pensamiento maduro (1980-1983) defiende que la raíz del problema metodológico a la hora de pensar, tanto al hombre, como al universo en el que este se encuentra, ésta en el hecho de que la filosofía ha caído con frecuencia en un proceso de «logificación de la intelección», correlativo a un proceso de «entificación de la realidad». Se debe, a juicio de Zubiri, volver a la raíz, a la realidad, y a la intelección de la realidad. Así, trató de superar tal «entificación de la realidad» tratando de mostrar que la noción de «inteligencia» que se había manejado hasta entonces carecía de radicalidad: oponiéndose tanto a Heidegger como a Husserl y Kant, abrió un nuevo ámbito de trascendentalidad física, arraigando al hombre siempre en su animalidad, a diferencia de Heidegger, y en su estar en la realidad con los demás hombres.

A partir del concepto de inteligencia sentiente, Zubiri trató de superar la «logificación de la inteligencia», que cae en un dualismo insolvente al disociar la sensibilidad de la inteligencia. El intento de Zubiri consiste, por tanto, en mostrar que ambas «potencias» conforman una sola facultad fundamental: el problema de fondo es, a partir de esta reflexión de Zubiri, el problema de la constitución formal del hombre y del acto de intelección sobre el mundo, un amplio y complejo problema que trató con prolijidad pero que, debido a su prematuro fallecimiento, dejó inconcluso.

También para él, así como para Rorty (1979/2004), la dificultad de construir una solución satisfactoria reside en la concepción dicotómica establecida a partir de Descartes, a quien debemos la noción de la «mente» como entidad diferenciada, y en la idea de Locke de una «teoría del conocimiento» basada en la comprensión de los "procesos mentales», así como en la noción de la filosofía como tribunal de la razón pura, idea que debemos a Kant.

Zubiri supera tal noción de «mente» como objeto de estudio particular, localizado en un espacio interno, conteniendo elementos o procesos que posibilitan el conocimiento. Introduciendo la categoría de «inteligencia sentiente», supera este impasse dicotómico y propone una nueva posibilidad poskantiana, entroncada en la tradición fenomenológica de Husserl y Heidegger, pero diferenciada de ella. En este sentido, puede ser fecundo establecer un diálogo entre las reflexiones zubirianas y las reflexiones damasianas, dos autores contemporáneos que se han valido de los conocimientos neurobiológicos de su tiempo para hacer frente a tan espinoso problema. 
Damásio ${ }^{2}$, por su parte, defiende la concepción de que el cerebro y el cuerpo forman un conjunto integrado por medio de circuitos reguladores bioquímicos y neurológicos mutuamente interactivos ${ }^{3}$. La mente deriva de ese conjunto estructural y funcional y no solamente del cerebro. Comprobaremos que las reflexiones de Zubiri parecen ubicarse en un línea afín a ésta.

En la historia de la investigación de la conciencia ${ }^{4}$ verificamos que esta cuestión deriva de la historia de la ciencia. En el siglo XVII, Descartes y Galileo marcaron la distinción entre una realidad física y la realidad mental del alma: el dualismo, la concepción inadecuada de la causalidad, comprendida como ocurriendo entre eventos diversos. Searle defiende que la causalidad implica una idea de propiedad, y no de entidades separadas.

La dificultad en el actual contexto intelectual es comprender cómo los procesos cerebrales (fenómenos objetivos públicamente observables) causan estados internos cualitativos de conocimiento y sensibilidad (particularmente a aquellos que los poseen). En el corazón y el núcleo de los estudios de la conciencia está el problema de la vinculación, en la medida en que actúa como el punto de encuentro de la neurociencia, la ciencia cognitiva ${ }^{5}$ y la filosofía de la mente .

¿Cómo transformar el misterio de la conciencia en el problema de la conciencia? El problema consiste en explicar cómo los procesos neurobiológicos en el cerebro «causan» nuestros estados subjetivos de conocimiento y sensibilidad. Con el «hiato explicativo» se concibe que la conciencia y sus procesos se constituyen a partir de procesos biológicos, siendo así una propiedad emergente del cerebro.

\footnotetext{
2 Damásio, A., The Feeling of What Happens: Body and Emotion in the Making of Consciousness, Harcourt Brace, New York, 1999.

3 Rosa, L. A., "The Theoretical and Scientific Problems of Damásio's Conceptual Model of Consciousness", Kriterion - Journal of Philosophy 32/2, 2018, 83-100.

4 Para mayor claridad, consideramos conveniente introducir la siguiente clarificación con respecto al uso del término "conciencia»: hasta el primer epígrafe (éste incluido), posee el significado psicológico usual, que también es tratado en neurociencia y que estaría más relacionado con la noción de "autoconciencia»; en el contexto de la investigación de Damásio, el término se utiliza para referirse a ella en los términos específicos en que lo hace Damásio, especialmente a través de las distinciones que plantea en The Feeling of What Happens: Body and Emotion in the Making of Consciousness y en Descartes' error; en el contexto de la filosofía de Zubiri, «conciencia» adquiere un significado fenomenológico especial, elucidado al inicio de Inteligencia y realidad, y que se refiere al momento del «darse cuenta de» que la inteligencia no efectúa en su primordialidad, es decir, no es un acto radical de la inteligencia, sino que es un acto derivado de lo primordial de la misma, que es la aprehensión primordial de realidad. Tres definiciones tan diferentes como complejas que, a nuestro juicio, pueden complementarse de modo fecundo.

5 Roskies A. L. «The binding problem», 1999, citado por: Thомаs, J. I. (2019). «Current Status of Consciousness Research from the Neuroscience Perspective», Acta Scientific Neurology $2 / 1,2019,40$.

6 Thomas, J., «Current Status of Consciousness Research from the Neuroscience Perspective», Acta Scientific Neurology, 2/1, 2019, 40.
} 
A este respecto, la perspectiva filosófica de Zubiri es, a nuestro juicio, una fecunda aportación a la reflexión por dos motivos: primero, por la propia forma como Zubiri entiende la filosofía y su relación con el conocimiento científico «El método zubiriano de análisis y conceptuación filosóficos cuenta con el conocimiento científico hasta para la elaboración de sus propios conceptos filosóficos, que en algunos casos provienen de las ciencias o están estrechamente ligados a ellas. Diego Gracia ha puesto de manifiesto algunos ejemplos bien significativos, como el caso de la noción de "sustantividad" $»^{7}$, central para entender la noción de "realidad» en la propuesta metafísica de Zubiri $^{8}$. Y también ocurre algo parecido en las nociones más básicas con las que Zubiri explicita los rasgos característicos de la intelección sentiente del hombre y que están estrechamente ligadas a los conocimientos de las ciencias biológicas $^{9}$ (la genética y la neurología) ${ }^{10}$. La segunda razón es más específica: Zubiri no cree en la separación entre sensibilidad e inteligencia. Aboga por considerar al hombre como una unidad íntegra, sin olvidar las raíces biológicas de la persona, de modo que llega a afirmar que el ser humano no posee, por un lado, una sensibilidad y, por otro, una inteligencia, sino que ambas cosas son una sola facultad inconsútil: ciertamente, sensibilidad e inteligencia son potencias irreductibles, pero no funcionan como facultades separadas en el hombre $^{11}$. La primera función de la inteligencia, nos dice, es biológica, y el ser humano solo puede comprenderse si comprendemos que su sensibilidad y su inteligencia conforman una compleja unidad, condición sine qua non para la existencia de la persona.

1. El Sentimiento como elemento fundamental de la conciencia: La Perspectiva DE ANTONio DAmÁsio

Damásio asume el presupuesto de que la mente existe dentro de un organismo integrado: sugiere que las «operaciones fisiológicas» denominadas «mente» derivan de un conjunto estructural y funcional y no solamente del cerebro (mente incorporada, y no solo cerebralizada); los fenómenos mentales son comprendidos en relación con el ambiente, el cual, en parte, es producto de la propia actividad del organismo (integración y equilibrio hombre/medio); el cerebro es entendido como poseedor de plasticidad funcional.

El cuerpo, tal como es representado en el cerebro, puede constituir el cuadro de referencia indispensable para los procesos neurales que experimentamos como siendo la mente (unidad de la naturaleza humana); la cuestión del «self»

7 ZubIRI, X., Sobre la realidad, Alianza, Madrid, 2001, p. 67.

8 Gracia, D., La cuestión del valor, Real Academia de Ciencias Morales y Políticas, Madrid, 2011, p. 49.

9 Conill, J., «¿Neurofilosofía en perspectiva zubiriana?», Arbor, 192/780, 2016, a326.

10 Íbid.

11 ZuBiRI, X., Inteligencia y realidad, Alianza, Madrid, 1998, p. 91. 
y del conocimiento son el núcleo de la conciencia, no siendo suficiente la descripción de cómo el cerebro crea imágenes mentales integradas y unificadas.

Las imágenes mentales son accesibles solo al organismo que las posee, pero pueden ser científicamente interpretables a partir de los correlatos comportamentales.

La conciencia presenta dos problemas ${ }^{12}$ : cómo el cerebro es capaz de transformar un patrón neural (objeto) en un patrón mental (imagen); cómo el cerebro hace emerger un sentido del yo de una perspectiva biológica:

[...] función biológica crítica que nos permite saber que estamos sintiendo tristeza, o alegría, sufrimiento o placer, vergüenza u orgullo $[\ldots]^{13}$.

Es un estado cualitativo de primera persona. No está separada de la emoción. Es el resultado de la integración de la actividad neural en diferentes regiones. Depende de las regiones que son más antiguas evolutivamente.

Siendo así, el acceso a la mente humana puede ocurrir por tres vías:

1. Manifestaciones externas observables: vigilia, emociones de fondo, comportamientos específicos

2. Manifestaciones internas relatadas por aquel que está siendo observado

3. Manifestaciones internas que los observadores pueden verificar en si mismos cuando se encuentran en circunstancias equivalentes a las del observado. Factores internos (relato) y externos (comportamiento), e interpretación de quien observa (experiencias personales).

\subsection{La «conciencia ampliada»}

De entre los conceptos acuñados por Damásio, el de conciencia ampliada tiene fuertes conexiones con la reflexión filosófica en la medida en que nos presenta cualidades inconfundiblemente humanas a niveles más elevados. La conciencia ampliada es caracterizada por Damásio como la etapa más evolucionada de la experiencia consciente. Va más allá del aquí y ahora de la conciencia central y nos da una visión general de nuestra vida individual y privada. La conciencia ampliada es el resultado del conjunto de recuerdos registrados por cada pulso de conciencia central y requiere memoria de trabajo para mantener las imágenes recuperadas por un tiempo. En él, el sentido de uno mismo surge en la exhibición de algunos de nuestros recuerdos personales, los objetos de nuestro pasado personal, aquellos que pueden dar sustancia a nuestra identidad, momento a momento ${ }^{14}$. Esta, con diferentes niveles de tiempo: aquí y ahora, pasado y presente en relación; a diferencia de la conciencia central, la ampliada está significativamente influenciada por la cultura y por el

12 Damásio, A., The Feeling of What Happens: Body and Emotion in the Making of Consciousness, o.c.

13 Ídem, p. 19.

14 Íbid. 
lenguaje. Crece con la evolución y las experiencias que cada individuo tiene a lo largo de la vida, y está vinculada al yo autobiográfico. Es la consecuencia de dos facultades: la capacidad de aprender y, con ello, de guardar registros de una infinidad de experiencias, conocidas previamente gracias a la conciencia central: y la capacidad de reactivar esos registros de modo que, como objetos, también puedan generar un sentido de si mismo en el acto de conocer y de ser conocido.

La conciencia ampliada y la memoria de trabajo no se confunden, sin embargo, ésta es un instrumento importante en el proceso de la primera. La memoria de trabajo permite que numerosas representaciones permanezcan en la mente por un largo periodo de tiempo, y que estén relacionadas.

La conciencia ampliada no se confunde con la inteligencia, pero es un requisito de esta en la medida en que la conciencia hace al organismo consciente de una mayor esfera de conocimiento posible, y la inteligencia tiene la capacidad de manipular el conocimiento con éxito, de modo que las respuestas inéditas puedan ser planteadas y ejecutadas.

Un organismo dotado de conciencia ampliada da muestras de conciencia de una gran esfera de conocimiento que no se encuentra solo en el medio externo, sino también en el interno. Al mismo tiempo, tiene la capacidad de plantear comportamientos complejos, no solo en el momento presente, sino también en el decurso de mayores intervalos de tiempo. Es necesaria para movilizar una amplia cantidad de conocimientos evocados en diferentes sistemas y modos sensoriales, y en la resolución de problemas.

En la síntesis de su pensamiento, podemos encontrar dos capacidades que pueden abrir una conexión con las reflexiones de Zubiri: la capacidad de elevarse sobre los dictados de ventaja y desventaja impuestos por las necesidades de la supervivencia; y la percepción crítica de discordancias, que lleva a buscar la verdad y el deseo de crear normas e ideales para el comportamiento y el análisis de los hechos (conciencia moral- el ápice de la distinción humana).

\section{Entre la AUtoconciencia de Damásio y la «Biografía» De ZubiRi}

Zubiri supera, como dijimos al inicio, tal noción de «mente» como objeto de estudio particular, localizado en un espacio interno, conteniendo elementos o procesos que hacen posible el conocimiento. Introduciendo la categoría de inteligencia sentiente, supera el impasse dicotómico, abriendo nuevas posibilidades en antropología y metafísica. En este sentido, puede ser fecundo el establecimiento de un diálogo entre Zubiri y Damásio, como decíamos.

A partir del concepto de inteligencia sentiente, Zubiri trata de superar la «logificación de la inteligencia», que cae en el dualismo, al disociar la sensibilidad y la inteligencia, unificando ambas «potencias» en una sola facultad fundamental, en la cual se encuentran integradas tanto la sensibilidad como la inteligencia: un modo de unión acerca del que Zubiri mismo afirmó que no 
puede disociarse en el viviente humano ${ }^{15}$. Por tanto, uno de los problemas de fondo es la constitución formal de la intelección del mundo y de las cosas que forman parte de él.

Damásio ${ }^{16}$ defiende la idea de que el cerebro y el cuerpo forman un conjunto integrado por medio de circuitos reguladores bioquímicos y neurológicos mutuamente interactivos. La mente deriva de ese conjunto estructural y funcional y no solo del cerebro.

Y a este respecto, Zubiri llega a afirmar que no se han de considerar el cerebro y la inteligencia como elementos separados o autónomos. No se pueden deslindar cuerpo y mente, porque el modo en que el ser humano existe como ser vivo es unitario, de modo que «El cerebro no es el órgano que intelige, tiene sentimientos y toma decisiones voluntarias, pero es el órgano que nos coloca en la situación de tener que inteligir, de tener que sentir afectos y de tener que tomar decisiones incluso para vivir orgánicamente» ${ }^{17}$. Cuerpo y mente se interpenetran, formando una unidad inconsútil que no puede ser considerada como segmentada o reducida a una operación unilateral, de la que la otra sería epifenómeno, ni por la vertiente racionalista, ni por la vertiente positivista. Una facultad única que, en diversas modalidades, nos abre a la pregunta y la necesidad por la verdad ${ }^{18}$.

A nuestro juicio, la noción de intimidad puede prestar buena asistencia en la tarea de conectar con las demás nociones, concretamente, a través de la noción de «biografía», ya que esta última noción se encuentra también en Damásio y, así lo creemos, puede cumplir un papel conectivo entre ambas reflexiones.

La noción de biografía en Zubiri surge a raíz de una reflexión acerca de las dimensiones social e histórica del ser humano, reflexión en la que la noción de tradición ${ }^{19}$ termina por tener un lugar destacado. En este contexto, Zubiri no olvida, como ya establecimos al inicio, que el hombre es un ser unitario, y no pueden separarse estas dimensiones de la consideración del ser humano como ser viviente. Así, la tradición que revierte en el individuo es la apropiación que el individuo hace del modo en que los demás le enseñan a enfrentarse a la vida, incluso si esta apropiación consiste en un rechazo frontal: y este momento de apropiación que se hace merced a nuestro modo concreto de ser personas en nuestras vidas, es la biografía ${ }^{20}$.

Es decir, que la biografía es el modo propio de vivir de un ser humano: de nuevo vemos que no hay separación radical entre lo más elevado de nuestras vidas, lo más puramente mental y lo animal, porque en el ser humano, ambas

15 ZuBIRI, Inteligencia y realidad, op. cit., p. 65.

16 Damásio, A., The Feeling of What Happens: Body and Emotion in the Making of Consciousness, o.c.

17 Zubiri, X., Sobre el hombre, Alianza, Madrid 1986.

18 Zubiri, X., Inteligencia y logos, Alianza, Madrid, 2002, p. 183.

19 Zubiri, X., Tres dimensiones del ser humano: individual, social, histórica, Alianza, Madrid, 2005, p. 78.

20 ZuBIRI, X., Sobre el hombre, op. cit., p. 124. 
cosas forman una unidad. Y todo ello por el hecho de que su forma de existir es lo que llamamos «ser persona», y es este modo de poseerse a uno mismo concretamente a lo que llama biografía Zubiri²1.

Conviene no perder de vista el hecho de que Zubiri es discípulo de Ortega y Gasset, para quien la vida humana es el sustrato básico y primordial al que hay que volver la vista para comprender la praxis del ser humano. Así lo evidencia cuando afirma que cuando hablamos de nuestra vida, no lo hacemos en sentido biológico, sino en sentido biográfico ${ }^{22}$.

Zubiri desarrolla el término «biografía» al hilo de una reflexión sobre los dos modos de transmisión que aparecen en el ser humano: la transmisión de caracteres naturales (herencia genética) y lo que él denomina "transmisión tradente», la tradición, que no es lo que suele comprenderse como tal en ese término. Precisamente hablando de «modos de estar en la realidad», esta tradición que se nos transmite por el hecho de existir en una realidad humana (teniendo unos progenitores, unas personas con las que convivimos, nuestra sociedad, nuestra cultura, nuestras comunidades, las personas que nos antecedieron y que nos sucederán, etc.) lo que nos transmite es un sistema de posibilidades con las que abrirnos paso en la realidad, porque «la tradición es un proceso por el cual se constituye el animal de realidades que nace» ${ }^{23}$. A este respecto, un absoluto abandono del ser humano en la realidad es ya un modo de situar al hombre en la realidad y, por tanto, una tradición, «el abandono mismo sería un modo de estar en la realidad $»^{24}$.

Este tipo de transmisión es exclusiva del ser humano y no podríamos, según Zubiri, encontrarla en ningún otro ser vivo. Pero no es algo que aparece en la especie humana por algún principio transfísico, sino que aparece (y así lo hace constar Zubiri) porque el hombre es, en primer lugar, un animal peculiar, un animal de realidades, y no de estímulos. Y por esta razón, la tradición y la historia lo son, no del individuo, sino de la especie humana. La tradición y la historia emergen de la animalidad del hombre, no hay ningún salto entre la animalidad y la humanidad que separe al hombre radicalmente de los animales. De hecho, como digo, Zubiri se refiere al hombre como «animal de realidades», los sentidos son el datum de la inteligencia ${ }^{25}$.

Un principio fundamental en Zubiri es que la vida es autoposesión: el viviente se posee en sus acciones para seguir existiendo, y de este modo, se va transformando. Se trata de una cuestión de poder, el poder de lo real, un punto de importancia fundamental en la filosofía de Zubiri, porque es este poder del

21 Zubiri, X., Siete ensayos de antropología filosófica, Centro de Enseñanza Desescolarizada, Bogotá 1982, p. 112.

22 Ortega, J., Unas lecciones de metafísica, Revista de Occidente, Madrid, 1974, Lección III.

23 ZuBiri, X., Sobre el hombre, op. cit., p. 79.

$24 \quad$ Ibíd.p. 80.

25 ZuBIRI, X., Inteligencia y razón, Alianza, Madrid, 1983, p. 32. 
que, constitutivamente, emergen la causalidad y los «rangos de lo real» ${ }^{26}, \mathrm{y}$ el modo en que el hombre se sabe ligado a la realidad en última instancia («religación») ${ }^{27}$. Para vivir, el viviente no puede mantenerse estático, y por eso es que Zubiri afirma que vivir consiste en ser el mismo, sin ser nunca lo mismo. Dado que la vida no es estática, sino que es «decurrente», cambiante, vivir consiste en auto-afirmarse (hacerse firme) en la realidad. La vida es autoafirmación en tensión dinámica: no solo movimiento, sino movimiento que se hace para seguir viviendo, y esto es la esencia de la vida.

Recordemos que la idea de la intimidad es precisamente la idea de una realidad que es mía: es la esencia de la intimidad, y eso abarca, como ya dijimos, desde el color de mi pelo hasta mi carácter y mi modo de hacerme cargo de las emociones $^{28}$, y es algo también orgánico, porque depende de un sentido físico al que Zubiri denomina «cenestesia», y pone junto a los cinco clásicos y otros nuevos a los que recurre para clarificar este punto:

Gracias a este sentir, el hombre está en si mismo. Es lo que llamamos intimidad. Intimidad significa, pura y simplemente, "realidad mía". Es un modo de presentación de lo real. La cenestesia en cierto modo es el sentido del "mi" en cuanto tal ${ }^{29}$.

A nuestro juicio, aquí se encuentra la diferencia esencial entre la simple conciencia y la conciencia que, con Damásio, llamaríamos ampliada, siempre teniendo en cuenta la diferencia entre el enfoque filosófico y el neurocientífico: la conciencia ampliada aparece cuando el ser humano comienza a ser consciente de que su vida se dilata en varias dimensiones: en pasado, presente y futuro, y esa dilatación adquiere, simultáneamente, un sentido unitario en el que los objetos ya no son estímulos inmediatos, sino que ocupan un lugar en ese background que es la vida misma del individuo, entre las constelaciones que configuran sus vivencias y sus expectativas. Desde la perspectiva de Zubiri, este carácter dilatado aparece cuando el hombre descubre que su vida es suya como ab-soluto, y esto no es posible hacerlo fuera de este contexto humano (sociedad, comunidad etc.) en el que los demás, tanto presentes como pasados, nos legan diversos modos

26 ZubIRI, X., Estructura dinámica de la realidad, Alianza, Madrid, 1995, p. 319.

27 Es el poder el que informa nuestras vidas, porque les damos forma confiriendo influencia a la realidad sobre nosotros, por libre elección o involuntariamente: de este modo es como tiene lugar el fenómeno de la apropiación y la autoposesión del viviente humano. El modo de hacer nuestra una posibilidad de nuestras vidas es dándole poder sobre nosotros para que nos informe. Y son estos poderes los que nos ponen en situación de tener que escoger entre diferentes posibilidades, y los que configuran en mayor o menor medida la forma de nuestro mundo. Esto es sumamente grave, porque significa que la forma que nos confiere una posibilidad apropiada nos domina: el homicida ya se ha apropiado la posibilidad de ser homicida, y nada de lo que haga podrá borrar el hecho de esa apropiación, porque ya la ha hecho efectiva, parte de su ser. Esto llama la atención sobre la gravedad de la vida, y la necesidad de permanecer vigilantes ante nuestras propias decisiones, tema que no desarrollaremos en el presente artículo.

28 Conill, J., Intimidad corporal y persona humana, Tecnos, Madrid, 2019, p. 78.

29 ZubIRI, X., Inteligencia y realidad, op. cit., p. 103. 
de hacernos cargo de nuestra vida: se trata de una dilatación que esencialmente ocurre al pasar de la estimulidad a la realidad como modo de enfrentarse con las cosas, y que abre tres ejes esenciales, la inteligencia sentiente, el sentimiento afectante, y la voluntad tendente como modos concretos de aprehender la realidad $^{30}$. Cuando tomamos esta «tradición» y la hacemos nuestra incorporándola a nuestras vidas (aunque sea para rechazarla), entonces hablamos de una biografía: las posibilidades que podemos escoger (apropiarnos) para nuestras vidas, son posibilidades que tenemos porque otros nos han ofrecido diversos modos de hacernos cargo de nuestra situación, y sobre estas posibilidades que los demás (tanto pasados como presentes, e incluso futuros) nos ofrecen, nosotros escogemos las posibilidades ${ }^{31}$ que queremos, y de ese modo, hacemos nuestra esta tradición y damos una nueva dimensión a nuestras vidas.

Para Damásio, en cambio:

La base neuronal para el yo, según lo veo, reside en la reactivación continua de al menos dos conjuntos de representaciones. Un conjunto se refiere a representaciones de eventos clave en la autobiografía de un individuo, sobre la base de los cuales se puede reconstruir una noción de identidad repetidamente, mediante activación parcial en mapas sensoriales organizados topológicamente [...] En resumen, la reactivación interminable de imágenes actualizadas sobre nuestra identidad (una combinación de recuerdos del pasado y del futuro planificado) propone una parte considerable del estado del yo tal como lo entiendo. El segundo conjunto de representaciones subyacentes al ser neuronal consiste en representaciones primordiales del cuerpo de un individuo ${ }^{32}$.

Esta conciencia ampliada de Damásio comprende la conciencia de un pasado, presente y futuro, unidos a mi por un sentido, que es ser mi vida, con todas mis vicisitudes y mis elecciones. Y esta vida ya no es una vida simplemente animal: se trata de una biografía. La conexión con Zubiri está ahí mismo: el hombre, según Zubiri, llega a humanizarse en este mundo humano en que consiste nuestra sociedad, nuestras comunidades, los otros con los que me encuentro en mi vida y que me ofrecen distintas posibilidades, distintos modos de hacerme cargo de mi realidad por muchas vías diferentes (la educación es una de ellas).

Damásio hablaría de conciencia, aunque Zubiri, por motivos filosóficos, emplea «inteligencia» ${ }^{33}$, y prefiere un enfoque en el que esta "conciencia ampliada» de Damásio, la capacidad para tener una autobiografía, para comprender $m i$ vida como unida por un sentido, en Zubiri sería el momento

30 Zubiri, X., Sobre el sentimiento y la volición, Alianza, Madrid, 1992, p. 221.

31 ZuBiri, X., El hombre, lo real y lo irreal, Alianza, Madrid, 2005.

32 DAmÁsio, A., Descartes' error: emotion, reason, and the human brain, G.P. Putnam, New York, 1994, pp. 238-239. La traducción es propia.

33 «Conciencia no es sino la sustantivación del «darse cuenta» mismo [...] no es verdad que lo que constituye la intelección sea el darse cuenta. Porque el darse cuenta es siempre un darse cuenta «de» algo que está presente a la conciencia. Y este estar presente no está determinado por el darse cuenta [...] Se trata ciertamente de un estar presente en la intelección», ZuBIRI, X., Inteligencia y realidad, op. cit., pp. 21-22. 
humanizador social e histórico al que nos abre nuestra inteligencia y nuestro existir con otras personas, entre los modos de esa inteligencia, la «intimidad», que nos permite asir esta vida como nuestra. En esta reflexión de Zubiri, ese momento humanizador en el que aparece la biografía, lo que en Damásio es ese modo especial de conciencia, es un rasgo humano fundamental, que nace de ese modo peculiar del hombre de poseerse que consiste en ser persona, en "aprehender» la vida como mía, como estando en la realidad, como una situación que me ofrece una serie de posibilidades entre las que yo tengo que escoger, de las que yo me tengo que apropiar para incorporarlas a mi vida, para hacerlas mías porque es el único modo que tengo de seguir existiendo y de alcanzar mi plenitud, que es algo que, como esta conciencia ampliada de Damásio, no aparece en animales que no posean esta peculiar capacidad para hacerse cargo de su vida, como la posee el ser humano, el animal de realidades.

\section{Conclusiones}

En el desarrollo de este trabajo hemos alcanzado seis conclusiones que resumen los puntos esenciales de este trabajo, y que pasamos a desgranar sucintamente en este apartado. De estas seis conclusiones críticas, cuatro nos señalan un acercamiento entre ambos autores analizados, y las dos últimas nos marcan las diferencias que enriquecen su aproximación mutua desde distintas disciplinas, diferencias de las que hemos de ser conscientes con el fin de no confundir sus respectivas aportaciones, ni restarles riqueza. Comencemos por las observaciones críticas.

En primer lugar, conviene recordar que, aunque convergentes a nuestro juicio, existe una diferencia fundamental entre la conciencia ampliada de Damásio y la reflexión de Zubiri: Damásio establece la conciencia ampliada como una capacidad de unificar presente, pasado y futuro en un sentido unitario para el individuo, capaz de integrar sus experiencias, memorias y elecciones en dicho contexto. La conciencia que habilita el cerebro ya no se limita al instante, sino que resulta expandida. Zubiri se plantea esta cuestión de la experiencia humanizadora desde una perspectiva filosófica, aunque interdisciplinar, como un momento de la tradición que recibe cada individuo, una expansión progresiva que tiene lugar merced a la apropiación de posibilidades facilitadas por los demás humanos. Lo fundamental aquí es el momento de apropiación, en el que ser humano hace su vida realmente suya, perteneciente a un Yo: pasado, presente y futuro surgen aquí, no como lo fundamental de la expansión de la conciencia, sino como un aspecto de la expansión que es la formalidad de realidad con todos sus aspectos humanos.

En segundo lugar, es necesario apuntar al uso terminológico: Damásio emplea el término "conciencia» para hablar de estas capacidades porque, para hablar del ser humano, resulta fundamental este momento de ser consciente de lo que ocurre. Como bien apunta ya en $Y$ el cerebro creó al hombre, no basta con 
la vigilia. Zubiri prefiere el uso de «inteligencia», un término más abarcante, a su juicio, que conciencia, debido a las complicaciones terminológicas que posee esta noción, especialmente desde la fenomenología, porque la conciencia consiste en un "darse cuenta», pero este momento, bien lo sabemos, es solo un tramo del largo camino que transita la inteligencia. Necesaria, eficaz y valiosa, sí, pero también zaguera a las operaciones elementales de la inteligencia.

En tercer lugar, que la conciencia ampliada que Damásio describe en sus trabajos es la capacidad mental definitoria del ser humano. Bien podríamos decir que es lo más humano del hombre: nuestro ser persona, nuestra capacidad para configurarnos a nosotros mismos como hombres, depende por completo de nuestra capacidad para enfrentarnos a nuestra vida como un todo con sentido en el que han de integrarse nuestras experiencias.

En cuarto lugar, conciencia ampliada no equivale a inteligencia en Damásio, aunque se trata de una condición para la existencia de esta. La inteligencia es capaz de manipular el conocimiento en orden a la resolución práctica: recordemos que la primera función de la inteligencia parece ser biológica. Pero esta capacidad no posee información que manipular si la conciencia ampliada no abre este mundo de conocimiento expandido para el hombre.

En quinto lugar, que en Damásio podemos encontrar capacidades que abren sus reflexiones a un contacto con el pensamiento de Zubiri. Concretamente, la capacidad para elevarse por encima de las necesidades inmediatas de supervivencia para reflexionar críticamente con el fin de hallar verdades, normas e ideales para el comportamiento. Es precisamente esta capacidad, nos dice Zubiri, la que diferencia al mero animal (sub-jectum de sus propiedades) del animal de realidades (super-jectum de sus propiedades). La verdad es un trascendental, hallado por la inteligencia, que organiza nuestras vidas ${ }^{34}$.

Por último, encontramos en Zubiri un concepto que aproxima su posición a la de Damásio y ayuda a esclarecer ambas reflexiones, como es la «inteligencia sentiente». Con este concepto. Zubiri pretende superar la noción tradicional de inteligencia, que tiende a separar de ella la sensibilidad, y a identificar «inteligencia» con «inteligencia judicativa», fenómeno al que Zubiri denomina «logificación de la inteligencia». A nuestro juicio, una posición cercana a Damásio, porque este autor trata, a su vez, de traer a primer plano el hecho de que toda inteligencia, todo cerebro, se encuentra en un cuerpo al que pertenece y a través del que funciona.

Con esta superposición de reflexiones fecundas, a nuestro juicio, es posible alcanzar una perspectiva más adecuada a la realidad humana, que nos aproxima otro paso al enigma de la conciencia, y nos permite comprender mejor qué nos hace humanos, y por qué esto que nos hace humanos no ha de estar separado de nuestro cuerpo y nuestra animalidad, sino que hemos de comprendernos como animales de realidades, con un cerebro que posibilita, pero no determina, que hallemos el sentido de nuestras vidas.

34 ZuBIRI, X., El hombre y la verdad, Alianza, Madrid, 2006. 
Deseamos mostrar nuestro más sincero agradecimiento al investigador de la Universidad de Valencia Jesús Conill, por sus fundamentales aportaciones a este trabajo de investigación.

\section{BiBLIOGRAFÍA}

Conill, J. (2016). «¿Neurofilosofía en perspectiva zubiriana?», Arbor, 192(780), a326.

- (2019). Intimidad corporal y persona humana. Madrid: Técnos.

Damásio, A. (1999). The Feeling of What Happens: Body and Emotion in the Making of Consciousness. New York: Harcourt Brace.

- (2003). Looking for Spinoza: Joy, Sorrow, and the Feeling Brain. New York: Harcourt Brace.

- (2010). Self comes to mind: constructing the conscious brain. New York: Pantheon Books.

- (1994). Descartes' error: emotion, reason, and the human brain. New York: G. P. Putnam.

Denett, D. (1991). Consciousness explained. Boston: Little Brown.

Gracia, D. (2011). La cuestión del valor. Madrid: Real Academia de Ciencias Morales y Políticas.

Ortega, J. (1974). Unas lecciones de metafísica. Madrid: Revista de Occidente.

Rosa, L. A. (2018). "The Theoretical and Scientific Problems of Damásio's Conceptual Model of Consciousness", Kriterion Journal of Philosophy, 32(2), 83-100.

Searle, J. (1998). Mind, language, and society. New York: Basic books.

Thomas, J. (2019). «Current Status of Consciousness Research from the Neuroscience Perspective», Acta Scientific Neurology, 2(1), 38-44.

Zubiri, X. (1982). Siete ensayos de antropología filosófica. Bogotá: Centro de Enseñanza Desescolarizada.

- (1983). Inteligencia y razón. Madrid: Alianza.

- (1986). Sobre el hombre. Madrid: Alianza.

- (1995). Sobre el sentimiento y la volición. Madrid: Alianza.

- (1995). Estructura dinámica de la realidad. Madrid: Alianza.

- (1998). Inteligencia y realidad. Madrid: Alianza.

- (2001). Sobre la realidad. Madrid: Alianza.

- (2002). Inteligencia y logos. Madrid: Alianza.

- (2005). El hombre, lo real y lo irreal. Madrid: Alianza.

- (2005). Tres dimensiones del ser humano: individual, social, histórica. Madrid: Alianza.

- (2006). El hombre y la verdad. Madrid: Alianza.

University Institute of Health Sciences,

Antonio Jácomo

Toxicology Research Unit, CESPU, CRL,

4585-116 Gandra, Portugal

ajacomo@porto.ucp.pt

Universitat de València

Carlos Sanmartín Catalán

Facultat de Filosofía i CC.EE

Departamento de Filosofía

Carlos.Sanmartin@uv.es

[Artículo aprobado para publicación en febrero de 2020] 